\title{
Holistic Management of Persons with Mental Disorders: Cases of Caregivers Center Psycho Neuro Pathology (CNPP) in Kinshasa in the DRC
}

\author{
Mukongo Kapita Joseph1, Kabongo Mwamba Andre Guillaume'2, \\ Bukasa Tshilonda Jean Christophe2, Kashala Td ${ }^{3}$, Kapenga Kasongo Jj3 \\ Mutombo Kabamba Andre ${ }^{4}$, Patricia Mishika Lukusa ${ }^{5}$, Wembonyama Okitotsho Stany ${ }^{5}$ \\ ${ }^{1}$ National Pedagogical University of Kinshasa, Kinshasa, Democratic Republic of Congo \\ ${ }^{2}$ Higher Institute of Medical Techniques of Mbujimayi, Mbujimayi, Democratic Republic of Congo \\ ${ }^{3}$ University of Kinshasa, Kinshasa, Democratic Republic of Congo \\ ${ }^{4}$ Official University of Mbuji-Mayi, Mbuji-Mayi, Democratic Republic of Congo \\ ${ }^{5}$ University of Lubumbashi, Lubumbashi, Democratic Republic of Congo \\ Email: jcbukasa4@gmail.com
}

How to cite this paper: Joseph, M.K., Guillaume, K.M.A., Christophe, B.T.J., Td, K., Jj, K.K., Andre, M.K., Lukusa, P.M. and Stany, W.O. (2019) Holistic Management of Persons with Mental Disorders: Cases of Caregivers Center Psycho Neuro Pathology (CNPP) in Kinshasa in the DRC. Open Access Library Journal, 6: e5558. https://doi.org/10.4236/oalib.1105558

Received: June 24, 2019

Accepted: August 23, 2019

Published: August 26, 2019

Copyright () 2019 by author(s) and Open Access Library Inc.

This work is licensed under the Creative Commons Attribution International License (CC BY 4.0).

http://creativecommons.org/licenses/by/4.0/

\section{(c) () Open Access}

\begin{abstract}
Introduction People with mental disorders are found in all countries of the world, but their support depends on each conceptual and organizational modality in strength in their respective countries. A serious problem arises in the holistic care of these patients by the fact that there is a lack of interest by their families, NGOs and the Congolese state, what grows them to be wandering day and night to across the major arteries of the Capital without any support, nor their admission to hospitals. The small group that can be admitted for care in hospitals, is also confronted with the institutional realities that do not allow that holistic care, especially since it takes days and the improvement seems to be too slow and mutigious. Why this study with caregivers to evaluate their work in relation to holistic care. Material and Method Our study is descriptive correlational. The study population is made up of 136 caregivers working at the Neuro Psycho-Pathological Center (CNPP) in Kinshasa, than we regarded to be an exhaustive sample given the importance of the study. To collect the data, we used the live observation, the interview and the questionnaires administered to the caregivers. The study was conducted for 1 month from 03.01.2019 to 01.04.2019. The SPSS software version 20 enabled us to analyze the data of our research by resorting to the statistical calculation commonly used for the frequencies. We have presented the p-value at the threshold of 0.5 . There is a significant link i.e. the p-value is from 0.001 to 0.499 , at this moment our time null hypothesis is maintained and in the case of p-value 0.501 to 0.999 . They are regarded as weakly significant, our assumption is automatically alternate.
\end{abstract}


Results The results showed that $53.8 \%$ of careers were between the ages of 41 $60 ; 69.8 \%$ of the male caregivers were compared to $30.8 \%$ female, $69.8 \%$ were the A3 nurses and $34.6 \%$ of these nurses had a seniority of $31-40$ years. The study shows also that working conditions of carers characterized by the lack of means of transportation at $96.2 \%$, the crisis turnover at $92.3 \%$. There are significant differences enter some socio-professional characteristics (qualifications and seniority) and the implementation by caregivers of standards-based patient care and the advancement of mental health, since all $\mathrm{p}$ values of $\mathrm{X}^{2}$ are less than 0.05. Therefore, being older and more qualified influences this application. Conclusion There are several laws around the world, including the Public Health Codes which include in their objectives the organization of a mental health service and the fight against mental illnesses, which implies the setting up of a Committee for the fight against mental illnesses and a structure that can take care of patients aftercare.

\section{Subject Areas}

Nursing

\section{Keywords}

Holistic Management, Mentally Ill, Right to Health

\section{Introduction}

Worldwide, according to ESEMeD-EPREMED international survey in 2005 estimated that a third of the French suffered at least one mental disorder in life, the fifth year. Anxiety disorders are predominant in frequency with $12 \%-13 \%$ of respondents. The diagnosis of severe depression had hit $2 \%-3 \%$ of the population in France against 3\% psychotic-like schizophrenia and just under 1\%. But regarding their holistic care in this country, the small group that can be admitted to hospital, is also confronted with institutional realities that do not allow holistic care, especially since it takes days. and the improvement seems to be too slow and slow [1]. Anxiety disorders are predominant in frequency with $12 \%-13 \%$ of respondents. The diagnosis of severe depression had hit $2 \%-3 \%$ of the population in France against 3\% psychotic-like schizophrenia and just under 1\%. But about their holistic care in this country, the three methods are used, namely the ambulatory method to receive the patient to mental health centers which only sectored institutions can provide the care and mission is to ensure the continuity to support, organize and coordinate all extramural activities in connection with the units of hospital care, the part-time support that include forms of PEC which do not involve hospitalization including consecutive day and night and welcome the versatile therapy and intensive care before moving towards reintegration, professional or night hospitals and PEC final time which in turn includes five modes: full-time hospitalization, the center of aftercare after the acute phase, therapeutic apartments with care units reintegration referred to the limited du- 
ration; home hospitalization of the patient according to his state and finally the investment therapeutic reception which is a suite or an alternative to full-time hospitalization professional or night hospitals and PEC final time which in turn includes five modes: full-time hospitalization, the center of aftercare after the acute phase, therapeutic apartments with units reintegration referred to care for the limited duration; home hospitalization of the patient according to his state and finally the investment therapeutic reception which is a suite or an alternative to full-time hospitalization professional or night hospitals and PEC final time which in turn includes five modes: full-time hospitalization, the center of aftercare after the acute phase, therapeutic apartments with units reintegration referred to care for the limited duration; home hospitalization of the patient according to his state and finally the investment therapeutic reception which is a suite or an alternative to full-time hospitalization [2].

The French law also states that the approach to the treatment course should ensure that people receive the right care by the right health care professionals at the right time and at the lowest cost and in good health structures [3].

People with mental disorders are found in all countries of the world, but their treatment depends on each conceptual and organizational modalities in force in their respective countries [4]. A serious problem in the holistic management of these patients by the fact that there is a disinterest by their families, NGOs and the Congolese state, prompting the latter to be wandering day and night through the main streets of the capital without any support or admission to hospitals [5]. But nevertheless a small group finds himself still supported hospital following the organization of their respective families.

In France and China, the care of people with mental disorders is through the Family Physicians, MHO, or the effective management of the state [6]. In Africa, the minimum conditions of mental health are not favorable in most countries. Several surveys have shown that not only hospitals are struggling to face financial problems, the poorly trained staff, but also, there is also lack of care equipment, organic frameworks that can deal with mental health and good support for mental deviance [7].

Indeed, Africa and the DRC, a small group of people with mental disorders can be admitted for care in hospitals, but often they are faced with the institutional realities that do not allow the holistic management especially that it takes many days and the improvement seems to be too slow and mutigieuse. Add to this the countless difficulties of conceptual and cultural on superstitious beliefs, magic, witchcraft, fetishism, the lack of appropriate structures for these patients, religious distortion revivalist churches and finally, poor living conditions [8].

It is this concern that has prompted us to conduct this study that pursues the main objective is to have the perception of people with mental disorders face was taking them into social and medical care by caregivers and families.

Given the above, we asked the questions of how is the care of mental patients by caregivers CNPP/MA? This support is it holistic? Does the professional qualifications of caregivers can they contribute to the proper holistic PEC mentally ill? 


\section{Materials and Methods}

Our study is descriptive correlational. The study population consisted of $136 \mathrm{ca}$ regivers working at the Center Neuro Psycho Pathology (CNPP) in Kinshasa, we have considered exhaustive sample given the importance of the study. To collect data, we used direct observation, maintenance and questionnaire administered to caregivers. The study was conducted for 1 month at either 01/03/2019 04/01/2019.

SPSS Version 20 and allowed us to make data analysis of our research by using the statistical calculation commonly used frequencies.

We appeared the p-value threshold of 0.5. There is a significant link ie the $\mathrm{p}$-value is 0.001 to 0.499 , at that time our null hypothesis is maintained and that if p-value 0.501 to 0.999 , they are considered weakly significant, our hypothesis is ex alternately.

\section{Results}

This section presents the results of the process of our research. They come from the analysis of issues and interviews with Nurses, present during our investigation.

Table 1 shows that $53.8 \%$ of caregivers had the age between $41-60$ years; $69.1 \%$ of caregivers were male against $30.9 \%$ female, $68.4 \%$ were more A3 nurses and $34.5 \%$ of nurses had seniority of $31-40$ years.

Table 2 shows that $96.3 \%$ of caregivers report that related to working conditions, transportation to get to the service is not insured, $92.6 \%$ of the staff say that all care is given on the basis of a rolling crisis service by the caregiver comes to the service two or three days a week and the rest of the day, he rests at home. In $30.4 \%$ of cases, the average stay of patients in the CNPP was between $4-6$ months and administration of patient care based on standards and the promotion of mental health is applied by caregivers that in $11.8 \%$ of cases. Existence CNPP drugs for good PEC mental patients, $94.1 \%$ of caregivers say that drugs exist, but lack of some molecules.

Table 3 shows that the differences between certain socio-professional characteristics (qualification and seniority) and has application by caregivers of patient care based on standards and the promotion of mental health are significant because all $\mathrm{X}^{2} \mathrm{p}$ values are less than 0.05 . So being the oldest and most qualified, influences this application.

\section{Discussion}

\subsection{Professional Social Features}

Fifty-three point eight percent of caregivers had the age between 41 - 60 years; $69.1 \%$ of caregivers were male against $30.9 \%$ female, $68.4 \%$ were more $\mathrm{A} 3$ nurses and $34.5 \%$ of nurses had seniority of $31-40$ years. These results support the observations made by the WHO [9] which stressed that age determines the ability of the person to cope with the health problems and also the level of education of 
nursing stakeholders is predictor of good quality care because most people have high qualification, the more they assume more responsibilities, which would place them in a situation where they are more likely to receive conflicting demands from their role.

Table 1. Distribution of Investigated according to the professional social features.

\begin{tabular}{cccc}
\hline variables & Modality & Size $\mathrm{N}=136$ & Percentage \\
\hline AGE & $21-30$ ans & 5 & 3.6 \\
$31-40$ ans & 21 & 15.4 \\
$41-50$ ans & 73 & 53.8 \\
& $51-60$ ANS & 21 & 15.4 \\
SEX & Fears and over & 16 & 11.8 \\
& Female & 42 & 30.9 \\
QUALIFICATION & Male & 94 & 69.1 \\
& Nurse A2 & 43 & 31.6 \\
SENIORITY & Nurse A3 & 93 & 68.4 \\
& Less than 10 years & 11 & 8 \\
& $11-20$ years & 21 & 15.4 \\
& $21-30$ ans & 40 & 29.4 \\
& $31-40$ ans & 47 & 34.5 \\
& $41-50$ ans & 16 & 11.7
\end{tabular}

Table 2. Distribution of Investigated by the organization of the care of the mentally ill.

\begin{tabular}{|c|c|c|c|}
\hline variables & Modality & Size $N=136$ & Percentage \\
\hline \multicolumn{4}{|l|}{ Working conditions } \\
\hline \multirow{2}{*}{ Transport to the CNPP } & Exist & 5 & 3.7 \\
\hline & No & 131 & 96.3 \\
\hline \multirow{2}{*}{ Bearing Type } & Crisis & 126 & 92.6 \\
\hline & Normal & 10 & 7.4 \\
\hline \multirow{5}{*}{$\begin{array}{l}\text { Average length of stay of the } \\
\text { patient }\end{array}$} & Less than 3 months & 31 & 22.8 \\
\hline & 4 - 6 months & 42 & 30.9 \\
\hline & 7 - 9 months & 31 & 22.8 \\
\hline & $10-12$ months & 21 & 15.4 \\
\hline & 13 months and more & 11 & 8.1 \\
\hline \multirow{3}{*}{$\begin{array}{l}\text { Application of patient care } \\
\text { based on standards and the } \\
\text { promotion of mental health }\end{array}$} & Caregivers apply & 16 & 11.8 \\
\hline & Caregivers do not apply & 120 & 88.2 \\
\hline & Medications exist & 2 & 1.5 \\
\hline \multirow[t]{2}{*}{$\begin{array}{l}\text { Existence CNPP drugs for } \\
\text { good PEC mentally ill }\end{array}$} & $\begin{array}{l}\text { The drugs exist, } \\
\text { but lack of some molecules }\end{array}$ & 128 & 94.1 \\
\hline & The drugs do not exist & 6 & 4.4 \\
\hline
\end{tabular}


Table 3. Association between socio-professional characteristics and haspplication by caregivers of patient care based on standards and the promotion of mental health.

\begin{tabular}{|c|c|c|c|c|c|c|}
\hline \multirow[t]{2}{*}{ Characteristics } & \multirow[t]{2}{*}{ Category } & \multicolumn{2}{|c|}{$\begin{array}{l}\text { Application by carers } \\
\text { patient care based on } \\
\text { standards and the } \\
\text { promotion of mental }\end{array}$} & \multirow[t]{2}{*}{$\mathrm{X}^{2}$} & \multirow[t]{2}{*}{ P-value } & \multirow[t]{2}{*}{ Meaning } \\
\hline & & apply & Do not apply & & & \\
\hline \multirow[t]{2}{*}{ AGE } & Less than 61 years & 12 & 108 & 2.81 & 0.59 & NS \\
\hline & Over 61 years & 4 & 12 & & & \\
\hline \multirow[t]{2}{*}{ SEX } & Female & 2 & 40 & 0.42 & 0513 & NS \\
\hline & Male & 14 & 80 & & & \\
\hline \multirow[t]{2}{*}{ QUALIFICATION } & Nurse A2 & 11 & 32 & 11.2 & $\underline{0.02}$ & S \\
\hline & Nurse A3 & 5 & 88 & & & \\
\hline \multirow[t]{2}{*}{ SENIORITY } & Less than 10 years & 6 & 1 & 9.8 & $\underline{0001}$ & $S$ \\
\hline & Over 10 years & 10 & 119 & & & \\
\hline
\end{tabular}

NS $=$ Not significant $S=$ Significant.

For their part, Brunet I., et al. [10] claim that the nurse is an expert when it has a care experience of about 4 years and more, but also with previous prerequisites. It will act much by intuition and see a situation generally in the presence of complex problems. On his way himself, it is flexible and innovative, which is not the case at the center.

\subsection{The Organization of Care for the Mentally Ill}

Ninety six point three percent of caregivers report that related to working conditions, transportation to get to the service is not insured, $92.6 \%$ of the staff say that all care is given based on a rolling crisis services by care who comes in two service or three days a week and the rest of the day, he rests at home. In $30.4 \%$ of cases, the average stay of patients in the CNPP was between $4-6$ months and administration of patient care based on standards and the promotion of mental health is applied by caregivers that in $11.8 \%$ of cases. Existence CNPP drugs for good PEC mental patients, $94.1 \%$ of caregivers say that drugs exist, but lack of a few molecules. For its part, Ruskin [11] reported that the hospital stay are other considerations that may have an adverse effect on the adaptive capacity and the condition of those hospitalized, including the status of the disease that can affect many body functions, a state of malnutrition, a general weakening, harmful drug interactions, extended stays CNPP and ageism prejudice. The same author also adds that there are several factors that contribute to reduce support networks inpatient namely: loss of professional role, which provided a network of acquaintances and friends; loss of mobility; the loss of prestige and power; the usual sources of support as well as illness and death. On this subject, Daniel Gélinas [12] rightly confirms that "there is no psychosocial intervention that has had a greater influence on the current services of the Community Mental Health 
that intensive treatment in the community" and appreciate work done by Allness and Knoedler in 1998 [13] to demonstrate the effectiveness of the model to follow and treat the natural environment, the most severely affected by mental illness people. Therefore, Seymour, JM [14] emphasized by saying that the nurse should have at its disposal a problem-solving tool: integrated care approach to a quality approach, it would highlight, from a collection of data, analysis of the situation and care targets that would aim to restore the healthy sick. Rolando wins [15] adds to clarify that in our time where people are open to health and legal responsibility, it is essential that the Nurses know the jurisdiction, to the extent of their responsibility under the State law in which they practice, compliance with professional duties, error prevention, decisions that are authoritative brand signs and nurse maturity. The Nurses have a special place for the mentally ill to adapt to the disease and to achieve this, they will help patients maintain their independence; strengthen their self-esteem; maintain support networks, to adapt to changes. They can use various therapeutics, including therapeutic listening, physical contact, the memories of the past, reality orientation and occupational therapy [16]. The absence of standards on the promotion of mental health and psychiatric center recognized by 23 (88.5\%) nurses, proves sufficiently that the offer of nursing in hospitalized mentally ill, has no legal base and prejudice this one. These services are offered in the blur part, difficult to assess and improve, confirming the hypothesis that the actual care are routine and devoid of good quality. Has no legal base and prejudice it. These services are offered in the blur part, difficult to assess and improve, confirming the hypothesis that the actual care are routine and devoid of good quality. [17] has no legal base and prejudice it. These services are offered in the blur part, difficult to assess and improve, confirming the hypothesis that the actual care are routine and devoid of good quality [17].

\section{Conclusion}

Worldwide, many laws exist, including public health codes that fall within their objectives, the organization of mental health services and the fight against mental illness, which involves the establishment of a committee fight against mental illness and a structure that can support patients in aftercare.

\section{Conflicts of Interest}

The authors declare no conflicts of interest regarding the publication of this paper.

\section{References}

[1] WHO (2000) Report on Mental Health in the World.

[2] Moraz, L. (2003) Take Charge of the Suffering in the Hospital, Patients, Caregivers, Family. Dunad, Paris.

[3] Lacabe, L., et al. (1997) The Rights of Man, an Anthology of Texts. Médiaspaul, 
Kinshasa.

[4] Kabula, A. (2014) CSM in Africa. SHSC 23/4/2014.

[5] WHO (2003) World Health Report in the World: Shaping the Future. WHO, Geneva.

[6] Henderson, V. (1969) Fundamentals of Nursing. S. Karger, Basel.

[7] Brunet, I., Lebeau, M. and Roy, M. (2007) The Preceptorship, a Partnership in Before-Garde. The Nursing Journal CHUM, 7, 24-26.

[8] Cohen, A. (2014) Facilitating Access Intellectual Disabilities to Mental Health Services in Psychiatric Care. No. 295.

[9] Daniel Gélinas. http://www.rsmq.com.org/smq/mental\%20health/article

[10] Seymour, J.M. (2007) The Nurse's Place in Psychiatry and Mental Health Today, in Psychiatric Care, No. 250, 31-34, 47.

[11] Win, R. (1970) Responsibilities and Obligations Regarding the Care of Sick. Intermode, Montreal.

[12] Bay, L. and Dind, I. (1992) Nursing Care in Rural Tropical Areas, Vol. 1, EMS.

[13] Duhamel, F. (1995) Health and the Family, a Systemic Approach in Nursing. In: Boucherville, Ed., Gaëtan Morin.

[14] Moreau, J. and Truchet, D. (1988) Rights to Public Health. Dalloz, Paris.

[15] (1981) Order of Nurses and Nurses of Quebec: Code of Ethics of Nurses, R.R.Q., c1-8, r4. Report of the International Conference on Primary Health Care, Quebec, 4-6.

[16] Dreess (2009) The Management of Mental Health.

[17] http://www.rsmq.com.org/smq/mental\%20health/article 